\title{
Using Technology and Customer Behaviour Characteristics to Improve Hotel Sales Performance
}

\author{
Stepan Chalupa ${ }^{1}$, Martin Petricek ${ }^{2}$ \\ ${ }^{1}$ Univerzity of Hradec Králové, Rokitanského 52, 15100, Hradec Kralove, Czech Republic \\ ${ }^{2}$ The Institute of Hospitality Management in Prague, Svidnicka 506, 18100, Prague, Czech Republic
}

\begin{abstract}
Booking window is one of the critical characteristics of customer behaviour that can influence hotel sales performance. Previous studies were focused mainly on the importance of booking window reporting in revenue management with lack of evaluation. This paper focuses on the evaluation of revenue management activities by analysis of customer behaviour with a focus on the use of modern technologies (Booking Engine, Channel Manager). Results show that the selected hotel is not following basic revenue management principles, which can be a reason for the year-to-year decrease in direct online sales and overall poor performance.
\end{abstract}

Keywords - Booking window, channel management, booking engine, hotel distribution, revenue management.

\section{Introduction}

The current hospitality industry is being highly influenced by the development of modern technologies, online platforms and increase of international tourists that are willing to travel and pay more than in previous years [1]. To stay competitive, hoteliers need to implement various software tools and applications like Property Management Systems, Web Booking Engines, Channel Management tools, Revenue Management tools and many others.

DOI: $10.18421 /$ TEM92-20

https://doi.org/10.18421/TEM92-20

Corresponding author: Stepan Chalupa, Univerzity of Hradec Králové, Rokitanského 52, 15100, Hradec Kralove, Czech Republic.

Email: chalupa@vsh.cz

Received: 05 February 2020.

Revised: 25 March 2020.

Accepted: 31 March 2020.

Published: 27 May 2020.

(c) BY-NC-ND (C) 2020 Stepan Chalupa \& Martin Petricek; published by UIKTEN. This work is licensed under the Creative Commons Attribution-NonCommercial-NoDerivs 3.0 License.

The article is published with Open Access at www.temjournal.com
The use of mentioned systems is directly connected to intensive data collection and processing. The ineffective use of these systems might be connected to economic loss. To benefit from these systems and mainly from the systems directly connected to revenue-generating departments of hotel operations, hoteliers should use the data appropriately and improve their revenue management strategy.

The key focus of modern hospitality-oriented research is in revenue management and customer behaviour identification. The main principles of revenue management are to sell the right product, to the right customer, for a right price, in a right time through right distribution channel with right distribution policy [2],[3].

This study connects the need for customer-oriented information systems uses with the main principles of revenue management to evaluate the sales performance of the selected hotel establishment. Within this study, customers booking behaviour is being identified using booking window characteristics (the time interval between the date of booking and check.in). [4]

The main goal of this study is to prove that hoteliers should use better available resources and their outputs to improve their overall performance. The data usage and ability to process them is not connected only with the level of professional experience, but with the level of general knowledge as well. Widening and strengthening of the knowledge which can be directly connected to professional promotion should be an integral part of the stimulation strategy of every company. [5]

\section{Literature Review}

Hotel Information System (HIS) is a set of various information systems simultaneously used to improve hotel operation efficiency. [6] Core of this system is being called PMS (Property Management Systems) which consists of the critical data and reporting for various departments based on used modules (FrontOffice, Housekeeping, Sales, Banquets and many others). [7] As proposed by other authors, hotel operators are using other systems like Customer 
Relationship Management (CRM) tools [5], the extranets of Global Distribution Systems and Online Travel Agencies, Meta-Search Engines and wholesalers' information systems. [8]

The distribution of hotel products is not connected with standalone systems, but their aggregation and bundle management, too. For the management of all the distribution channels from one solution, the Channel (Distribution) Management tools are being used with direct connectivity to Revenue Management tools to allocate the right amount of product on specific distribution channels and optimal price. [9]

When abstracting from distribution oriented systems, several other systems can be found within the complex HIS. Currently highly valued Reputation Management Systems, Supplier Relationship Management Tools, Supply Chain Management tools, Point-of-Sale systems (complex restaurant systems), and marketing tools for Search Engine Optimisation and Search Engine Marketing, Social Network, Content Management Systems for website creation and updates, and many more systems depending on the size and the needs of hotel operator.

When focusing on the distribution and revenue management, it is crucial from a hotel operator to investigate the performance of specific segments and their behaviour. One of the factors that are being used not only within marketing, but in revenue management is time as well. The factor of time places both hotel operators and guests into a certain level of uncertainty where customers may face the situation of highly-priced last-minute bookings and hoteliers loss of the revenue. [10] Some customers are trying to reduce the level of uncertainty by booking in advance [11]. This advanced booking is reflecting on the customer's price sensitivity. Pricedemand sensitivity is used to describe how the demanded quantity will change if the price is being changed. In other words, price-sensitive market segments are reacting by their booking behaviour on the demanded volume of rooms where the priceinsensitive market segments do not change the demanded volume, while price change is being identified.

Booking window, or advanced booking information, is used by many authors to predict the performance of the specific market segment. [12] [13]

Tracking the time variable that describes customer behaviour can be used for dynamic price setting and adjustments to limit or stimulate the right market segment in the right. That to price manipulations, hotel operator can easily control their occupancy while maintaining suitable profitability level. [14] In the study of Jang, Chen \& Miao [15] the authors described last-minute booking behaviour of hotel customers while focusing on very short time-span of 0-2 days. The findings show that these clients are having significantly shorter decision-making process while focusing mainly on the presented price, best deals, room availability and the guest reviews. Other findings of this study show a lack of information research and lower evaluated possibilities. When focusing on longer time-span segments, price is still the most important evaluation factor, but the longer time before arriving the client do the research, the more details about the stay the client wants. Assuming above mentioned information and results of studies focused on last-minute deals and product selling, discounting can be a great tool to improve the poor performance of the hotel in a short time.

Contrary to these results, other authors are proposing more sophisticated and long-term oriented revenue management strategy while mentioning the inefficiency of hotel room discounts. [16],[17]

Both studies are proposing the opposite approach of "bottom-up" pricing in contrary to "top-down" pricing. Bottom-up pricing is based on the fact that that in long-term, customers are spending a significant amount of time on research and evaluation of definite possibilities, where still the price is the number one factor. Thanks to lower rates, hotel operators are more competitive and sell more room in advance to reach a suitable level of occupancy and to prepare for dynamic price growth in the shorter time-span. Thanks to this approach, insensitive price customer may face the situation of feeling the lack of opportunities and book the higher priced room (as they do not spend so much time in research). To be visible for these customers, the hotel should implement complex reputation management a marketing strategy.

This approach confirms the findings of Lee [18], in which discounting is mainly used to improve abysmal hotel performance caused by previously underestimated demand and incorrectly prosecuted distribution and pricing strategy.

The using of booking window characteristic is critical for revenue and marketing manager to effectively set, manage and control all the activities to reach the hotel goal. As mentioned in the definition of revenue management, timing is of the most critical factors to succeed, gain and maintain the competitive advantage and long-term profitability.

\section{Method and Data}

To achieve the goal, this study focuses on the performance of hotel in years 2018 and 2019, mainly on the booking window of reservations, their volume and average rate (in this case, Average ADR is used). 
The data are exported from Channel Manager which aggregate all the online hotel reservations. This tool is connected to hotel PMS to enable smooth operations and reservation administration. During these periods, reservations from WBE (Web Booking Engine), Booking.com and Expedia.com were collected.

In total, 2380 reservation were observed (1455 in 2018 and 925 in 2019). As the hotel was not keeping the rate parity strategy (strategy of selling the same products on all the platforms for the same rate), the selling rate varies for selected distribution channel and period. The selling rates shifted on average higher form 2018 to 2019. The highest selling rates were identified for WBE in 2019 and the lower for Expedia.com for 2018. Selling rates were observed in local currency for Czech Republic (Czech Koruna CZK) where 1 EUR equals approximately to 25 CZK. Average selling rates for WBE were in 2018 $4858 \mathrm{CZK}$ and $4988 \mathrm{CZK}$ in 2019. For Booking.com, average selling rate for 2018 was 3839 CZK and 4059 CZK for 2019. The lowest selling rates were identified on Expedia.com; wherein 2018, the average selling rates was 2137 CZK and 3210 CZK in 2019.

Observed data were visualised in a simple table processor to show to the simplicity of the data processing and use within revenue and marketing strategy. Two main diagrams were used to describe the booking behaviour of hotel customers and the behaviour of hotel revenue manager while setting selling rates and availability. Booking pace diagram was used in many previous studies mainly to describe group business or evaluation of selling activities for a specific date during the year. [19],[20],[21]

The previously mentioned booking window was used to describe more variables as well, not only the total evaluation of sales, for example, the ADR or RevPAR and their total contribution performance of the hotel establishment [22].

\section{Results}

Based on the observed data, several simple outputs were created to evaluate the performance of online hotel sales.

This evaluation is possible only due to the intensive use of technologies within the hotel. It is essential to mention that selected hotel is not using a revenue management system, only the pre-set strategy to reach the growth in RevPAR (Revenue per Available Room) and total efficiency in hotel operations. To evaluate the hotel performance, reservations from direct hotel websites were used.

Figure 1 shows the total description of the observed transaction data. In general, from 2018 to 2019, the hotel changed the strategy and improved the pricing strategy in terms of the price increase. This increased price caused the immediate decrease in the number of reservations. Unfortunately, this was reported as insufficient situation not evaluating the total performance of the hotel. Thanks to the aggregation of the data within Channel Manager, hotel operator should be able to evaluate total performance, not only the partial key performance indicators. When focusing on the total revenue from accommodation services through WBE, in 2018, the total reported revenue from reservations gained through the website was 3098436 CZK. In 2019, the total reported revenue decreased by more than $25 \%$ to $2313248 \mathrm{CZK}$. Using the booking window, the highest difference was identified within the periods of 90+, 15-30 and 0-1 day prior arrival. When focusing on these periods, it is quite clear that hotel revenue manager tried to improve the pricing strategy based on the last year performance, thanks to the high demand for "firs-minute" reservations the average rate was increased to eliminate the demand in "first-minute" reservation segment which was as well connected to highest level of cancellations (Cancellation Policy of the hotel is focusing mainly of these "first-minute" reservations by which the full refund of selling rates is being applied for cancellations more than 30 days prior the arrival).

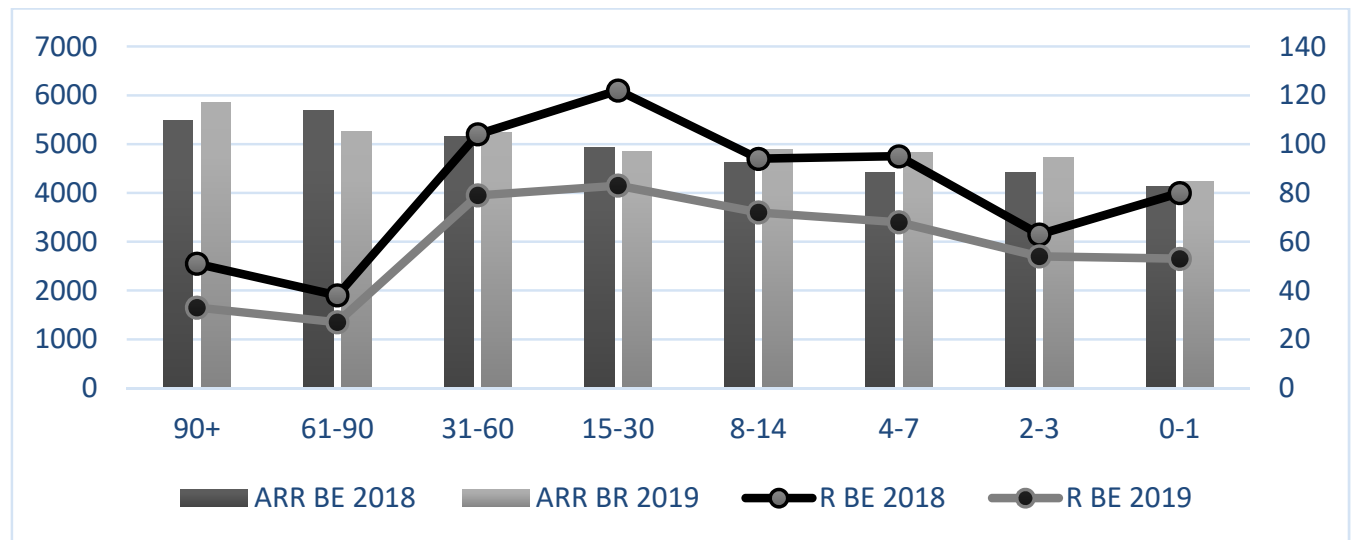

Figure 1. Evolution of average ADR and number of reservations in Booking Window in 2018 and 2019 
The second reason for this step was to eliminate the fast selling-out of the hotel to keep the unoccupied rooms for further selling and application of revenue management principles (mainly the "bottom-up" pricing principle). Unfortunately, this principle was not applied as can be seen on the evolution of average ADR for specific periods in both years. Within Figure 1, there can be identified a significant difference in the number of reservations received from 15 to 30 days before arrival.

This was mainly caused by a significant decrease in selling prices in 2018, on the other hand, the decrease in 2019, which was even more significant was not connected to such an increase in a number of reservations. This leads to the conclusion that the behaviour of customers using WBE changed during the year. To verify this problem, the booking pace diagram was created as a cumulative relative volume of reservations in booking window periods.

Figure 2 describes this diagram. As can be seen, there is no direct difference within the customers' behaviour in terms of timing their booking decision. From the customer's perspective, there should be a different factor causing overall demand decrease.

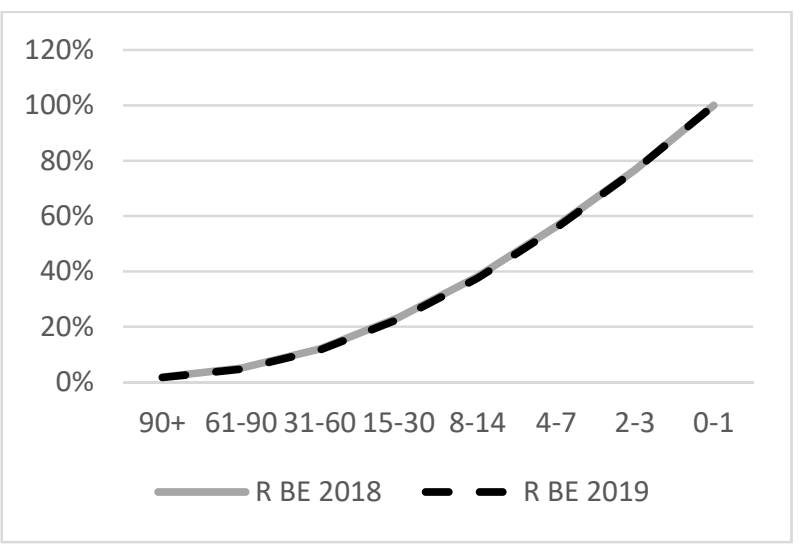

Figure 2. Booking pace diagram for reservation from $W B E$

As there is no evidence of change in customer behaviour, the decrease in hotel performance should be investigated from a different point of view. Hotel revenue manager is using a "top-down" pricing strategy which is commonly applied for reduction of demand long-term prior arrival. This strategy should be changed when reaching the specific point where the demand starts growing, that means when the highest demand is being observed (in our case from 14 to 60 days). This time-span is too broad and should be narrowed by a deeper analysis of time categories.
When focusing on price only, it is quite clear that the hotel is struggling in customer acquisition within the last two weeks before the customer's arrival. This information should be implemented not only in pricing but as well in distribution and communication strategy. Still decreasing selling price shows the need for more customers with a lack of their reaction measured by the volume of realised bookings. Comprehensive knowledge customers and not only their behaviour should be used.

Analysing not only customer booking behaviour, but other characteristics as well, a hotel revenue manager should understand the main motives of customers adequately and find better communication and distribution ways to reach them. From this perspective, two different customer segments were identified not only based on their booking behaviour but as well based on the products booked and applied cancellation policy.

- Individual traveller. These customers are shopping on average seven days before arrival and creates nearly $75 \%$ of the customers. As proposed in the literature review, these customers are focusing on the lowest possible rate, while hotel should benefit from the lack of information research. Their average booking rate is 4678 CZK which is nearly by $500 \mathrm{CZK}$ lower than expenses of the following segment. Thank application of above mentioned cancellation policy, these segments do as well expect lower rate due to impossibility of cancelling the reservation and prepayments.

- Product package buyers. The second group of customers consist mainly of the customers who booked the product package (the expenses for other services are excluded from the selling price). The average booking rate for accommodation within the product package was 5299 CZK. The product packages are having the same cancellation policy, but they are the more complex product, which is accompanied by other services (mainly the wellness and sport activities discounts and free entries).

Both presented approaches for the description of customer behaviours (based on the booking patterns and booked products) are relevant for planning the revenue management strategy. In the scope of this article, there should be strong differentiation between identified segments. Within long-terms, hotel manager should maximise the efforts to attract product package buyers in higher volume which should lead to an increase in selling rates for individual travellers.

The current strategy of "top-down" pricing snows lack data use and knowledge application while using modern technologies and approaches within revenue management. 


\section{Conclusion}

Previously mentioned results and outputs of data extraction and aggregation from Channel Management tool and their processing shows how easily hotel revenue managers can use the available data and automise reporting to improve hotel revenue management strategy and overall hotel performance. There are two primary outputs of this study. Application of modern technologies in hotel operations should be directly connected to knowledge improvement, not only on the level of systems usage but as well on the level of general knowledge of selected activities. The standalone ownership can improve or worsen the efficiency of hotel operations based on the level and way of usage.

According to the results presented in the previous section, the hotel should reset the revenue management strategy and focus more on the data provided by the channel manager or other systems that are part of the HIS. Better segmentation and knowledge of the customers can lead to crucial improvements in distribution and pricing strategy which is beneficial for the whole hotel operations.

Further research should focus on the interoperability of the systems and a better understanding of customers' behaviour using advanced statistical tools and methods as well. This behavioural knowledge should be combined with theoretical economic concepts to improve the revenue management strategy, too.

\section{References}

[1]. Mace, J., Skupinova, S., \& Smotlachova, E. (2018). Tourist Arrivals from Distant Countries to the Czech Republic in 2012-2018. In K.S. Soliman (editor), Innovation Management and Education Excellence Through Vision 2020, Vols I-IX. Italy: Milan, International Business, Information, Management Association.

[2]. Vives, A., Jacob, M., \& Payeras, M. (2018). Revenue management and price optimization techniques in the hotel sector: A critical literature review. Tourism Economics, 24(6), 720-752.

[3]. Abrate, G., Nicolau, J. L., \& Viglia, G. (2019). The impact of dynamic price variability on revenue maximization. Tourism Management, 74, 224-233.

[4]. Arenoe, B., \& van der Rest, J. P. I. (2019). Does Willingness to Pay for Rate Conditions Depend on the Booking Window? A Novel Time-Dependent Conjoint Analysis Approach. Cornell Hospitality Quarterly, 6(2), 213-222.

[5]. Leung, R., \& Law, R. (2013). Evaluation of hotel information technologies and EDI adoption: The perspective of hotel IT managers in Hong Kong. Cornell Hospitality Quarterly, 54(1), 25-37.

[6]. Pop, M. (2016). Motivation and Stimulation as a Key Instrument of Employees Stabilization. In P. Slavickova (editor), Knowledge for market use 2016: Our Interconnected and Divided World (pp. 364-368). Olomouc: Palacky University, Department of Applied Economics.
[7]. Melián-Alzola, L., Fernández-Monroy, M., \& Hidalgo-Peñate, M. (2020). Information technology capability and organisational agility: A study in the Canary Islands hotel industry. Tourism Management Perspectives, 33, 100606.

[8]. Lei, S. S. I., Nicolau, J. L., \& Wang, D. (2019). The impact of distribution channels on budget hotel performance. International Journal of Hospitality Management, 81, 141-149.

[9]. Ivanov, S., \& Ayas, Ç. (2017). Investigation of the revenue management practices of accommodation establishments in Turkey: An exploratory study. Tourism management perspectives, 22, 137149.

[10]. Ng, I. C. (2007). Advance demand and a critical analysis of revenue management. The Service Industries Journal, 27(5), 525-548.

[11]. Shugan, S. M., \& Xie, J. (2004). Advance selling for services. California Management Review, 46(3), 3754.

[12]. Lee, M. (2018). Modeling and forecasting hotel room demand based on advance booking information. Tourism Management, 66, 62-71.

[13]. Chen, C., \& Kachani, S. (2007). Forecasting and optimisation for hotel revenue management. Journal of revenue and pricing management, 6(3), 163-174.

[14]. Mohammed, I., Guillet, B. D., \& Law, R. (2019). Last-minute hotel-booking and frequency of dynamic price adjustments of hotel rooms in a cosmopolitan tourism city. Journal of Hospitality and Tourism Management, 41, 12-18.

[15]. Jang, Y., Chen, C. C., \& Miao, L. (2019). Lastminute hotel-booking behavior: The impact of time on decision-making. Journal of Hospitality and Tourism Management, 38, 49-57.

[16]. Ivanov, S., \& Ayas, Ç. (2017). Investigation of the revenue management practices of accommodation establishments in Turkey: An exploratory study. Tourism management perspectives, 22, 137149.

[17]. Enz, C. A., Canina, L., \& Lomanno, M. (2004). Why discounting doesn't work: The dynamics of rising occupancy and falling revenue among competitors. Cornell University, Center for Hospitality Research.

[18]. Lee, S. H. (2016). How hotel managers decide to discount room rates: A conjoint analysis. International Journal of Hospitality Management, 52, 68-77.

[19]. Kimes, S. E., \& McGuire, K. A. (2001). Functionspace revenue management: a case study from Singapore. Cornell Hotel and Restaurant Administration Quarterly, 42(6), 33-46.

[20]. Rottembourg, B., \& Masson, J. (2017). When bid price is not enough: Taking better allotment decisions for Camping Revenue Management. Journal of Revenue and Pricing Management, 16(2), 115-124.

[21]. Liu, P. H., Smith, S., Orkin, E. B., \& Carey, G. (2002). Estimating unconstrained hotel demand based on censored booking data. Journal of Revenue and pricing Management, 1(2), 121-138

[22]. Buckhiester, B. (2011). Revenue management as a multi-disciplinary business process: part two. The Journal of Hospitality Financial Management, 19(2), 97-113. 